\title{
RESEARCH
}

Open Access

\section{Medication risk management and health equity in New Zealand general practice: a retrospective cross-sectional study}

\author{
Sharon Leitch ${ }^{1 *}$ D, Jiaxu Zeng ${ }^{2}$, Alesha Smith ${ }^{3}$ and Tim Stokes ${ }^{1}$
}

\begin{abstract}
Background: Despite an overt commitment to equity, health inequities are evident throughout Aotearoa New Zealand. A general practice electronic alert system was developed to notify clinicians about their patient's risk of harm due to their pre-existing medical conditions or current medication. We aimed to determine whether there were any disparities in clinician action taken on the alert based on patient ethnicity or other demographic factors.

Methods: Sixty-six New Zealand general practices from throughout New Zealand participated. Data were available for 1611 alerts detected for 1582 patients between 1 and 2018 and 1 July 2019. The primary outcome was whether action was taken following an alert or not. Logistic regression was used to assess if patients of one ethnicity group were more or less likely to have action taken. Potential confounders considered in the analyses include patient age, gender, ethnicity, socio-economic deprivation, number of long term diagnoses and number of long term medications.

Results: No evidence of a difference was found in the odds of having action taken amongst ethnicity groups, however the estimated odds for Māori and Pasifika patients were lower compared to the European group (Māori OR 0.88, $95 \% \mathrm{Cl}$ 0.63-1.22; Pasifika OR 0.88, $95 \% \mathrm{Cl}$ 0.52-1.49). Females had significantly lower odds of having action taken compared to males (OR 0.76, $95 \% \mathrm{Cl}$ 0.59-0.96).

Conclusions: This analysis of data arising from a general practice electronic alert system in New Zealand found clinicians typically took action on those alerts. However, clinicians appear to take less action for women and Māori and Pasifika patients. Use of a targeted alert system has the potential to mitigate risk from medication-related harm. Recognising clinician biases may improve the equitability of health care provision.
\end{abstract}

Keywords: Ethnicity, Equity, Decision support, General practice, Harm

\section{Background}

Health inequities are defined as differences in health outcomes or risks to health between peoples of different social advantage [1]. Te Tiriti O Waitangi (The Treaty of Waitangi), the founding constitutional document of Aotearoa New Zealand (NZ),

\footnotetext{
* Correspondence: sharon.leitch@otago.ac.nz

'Department of General Practice and Rural Health, Otago Medical School Dunedin Campus, University of Otago, Dunedin, New Zealand

Full list of author information is available at the end of the article
}

upholds the ideals of equity and protection of Māori (the Indigenous people) [2-4].

New Zealand provides universal cover for most health services, including hospital-based inpatient and outpatient care [5]. Primary healthcare is delivered in community-based general practices. General practice services and medication for children under the age of 14 years are fully subsidised. However, most other patients co-pay for primary healthcare (typically \$13 -\$35 USD) and pay a small prescription charge per medication

C C The Author(s). 2021 Open Access This article is licensed under a Creative Commons Attribution 4.0 International License, which permits use, sharing, adaptation, distribution and reproduction in any medium or format, as long as you give appropriate credit to the original author(s) and the source, provide a link to the Creative Commons licence, and indicate if changes were made. The images or other third party material in this article are included in the article's Creative Commons licence, unless indicated otherwise in a credit line to the material. If material is not included in the article's Creative Commons licence and your intended use is not permitted by statutory regulation or exceeds the permitted use, you will need to obtain permission directly from the copyright holder. To view a copy of this licence, visit http://creativecommons.org/licenses/by/4.0/ The Creative Commons Public Domain Dedication waiver (http://creativecommons.org/publicdomain/zero/1.0/) applies to the data made available in this article, unless otherwise stated in a credit line to the data. 
(\$3.50 USD). Annual out-of-pocket health spending per capita is $\$ 520$ USD, accounting for around $12 \%$ of New Zealand total health spending [6]. In comparison, the median weekly income is \$455 USD; Māori and Pasifika (people living in NZ who identify as Pacific peoples) have lower median weekly incomes than people of other ethnicities [7].

Systemic racism is widespread in the New Zealand health system [8]. Despite ambitious national goals to "improve, promote and protect the health and wellbeing of New Zealanders" [9], healthcare inequity persists for Māori and Pasifika [10]. People of Māori and Pasifika ethnicity and people who experience socioeconomic deprivation, have excessively high adverse event rates, including premature mortality, injury, disability, and healthcare-related harms [10-15]. These groups experience under-prescribing of appropriate medications, higher prescribing of inappropriate medications [16], and higher rates of polypharmacy $[17,18]$.

Computerised decision support tools can help improve the quality and safety of prescribing by identifying and alerting clinicians to potentially dangerous prescribing actions [19-22]. Conporto Health Event Detection \& Mitigation (Conporto EDM) is an automated alert system that detects whether general practice patients are at high risk of medical harm due to their medical conditions, medications, or for want of mitigating preventative action [23]. Events in this system consist of 10 pre-specified conditions (Table 1). The system is triggered by activities such as making an appointment, or a prescription request. Clinicians are informed at the start of each session which of their patients to be seen are at increased risk of harm via secure email, with detailed information sent to the electronic health record "Inbox". The "Inbox" is a portal containing all messages relevant to that patient, including laboratory results, radiology results, correspondence from secondary care, and Conporto EDM alerts. Clinicians have full discretion as to whether they act on the Conporto EDM alerts. Patients are not advised of the alerts unless informed by their clinician. In an attempt to avoid alert fatigue, clinicians are only notified of each triggered Conporto EDM alert once every three months. Therefore, if a Conporto EDM alert is triggered by the patient making an appointment or requesting more medication within three months since the last alert, the clinician will not be notified of those alerts.

Preliminary analysis of Conporto EDM data from 1 March - 31 October 2018 was undertaken by Conporto Health [23]. This suggested that although general practitioners did generally take action following an event alert notification, when analysed by individual harm event they appeared less likely to take action for Māori and Pasifika patients [23]. However, important confounders were not adjusted for in those analyses. Also, action rates were evaluated by individual event, even though four of the event groups were too small to make statistical inferences when broken down by ethnicity. We therefore re-examined the association between the actions clinicians took after receiving an event alert and patient ethnicity to determinate robustness of the earlier findings. We did this by grouping all alerts to look at action taken as a whole rather than by individual event, and adjusting for a set of important confounders.

The aim of this study is to determine whether there were any disparities in clinician action taken (versus no action) following an alert based on patient ethnicity or other demographic factors.

Table 1 Conporto EDM alerts

\begin{tabular}{|c|c|c|}
\hline & Alert & Description \\
\hline 1 & $\begin{array}{l}\text { Allopurinol > } 200 \mathrm{mg} \\
\mathrm{eGFR}<30\end{array}$ & $\begin{array}{l}\text { Allopurinol prescribed at a dose of }>200 \mathrm{mg} / \text { day to a patient with chronic renal insufficiency }(\mathrm{eGFR}<30 \mathrm{~mL} / \mathrm{min} / \\
\left.1.73 \mathrm{~m}^{2}\right)^{\mathrm{a}}\end{array}$ \\
\hline 2 & Macrolide \& simvastatin & Prescription for an macrolide antibiotic, with a co-prescription for simvastatin \\
\hline 3 & Bupropion epilepsy & Bupropion (Zyban) prescribed to a patient with epilepsy \\
\hline 4 & Metformin eGFR $<30$ & Metformin prescribed to a patient with renal insufficiency where the eGFR is $<30 \mathrm{~mL} / \mathrm{min} / 1.73 \mathrm{~m}^{2}$ \\
\hline 5 & MTX no Folic acid & Prescription of methotrexate, without a co-prescription for folic acid \\
\hline 6 & NSAID eGFR $<45$ & Prescription of a NSAID ${ }^{b}$, in a patient with chronic renal insufficiency (eGFR $<45 \mathrm{~mL} / \mathrm{min} / 1.73 \mathrm{~m}^{2}$ ) \\
\hline 7 & NSAID, Ulcer, no PPI & $\begin{array}{l}\text { Prescription of a NSAID, without co-prescription for an proton-pump inhibitor to a patient with a history of peptic } \\
\text { ulceration }\end{array}$ \\
\hline 8 & PDEi \& Nitrite & Prescription of a phosphodiesterase type-5 inhibitor, with a co-prescription for a nitrate \\
\hline 9 & Valproate F epilepsy & $\begin{array}{l}\text { Prescription of sodium valproate to a female aged 10-59 years with a diagnosis of epilepsy, without history of } \\
\text { hysterectomy }\end{array}$ \\
\hline 10 & Valproate F & Prescription of sodium valproate to a female aged 10-59 years, without history of hysterectomy OR epilepsy \\
\hline
\end{tabular}

${ }^{a}$ eGFR estimated glomerular filtration rate, specified here as having been calculated with the Cockcroft-Gault equation

${ }^{\mathrm{b}}$ NSAID Non-steroidal anti-inflammatory drug, e.g. aspirin, ibuprofen, diclofenac, etc. 


\section{Methods}

General practices were recruited from all regions of New Zealand, from those participating in the Conporto Health Look-Up programme (an online platform presenting an integrated summary patient record between healthcare providers). Sixty-six practices signed a consent form to participate in the Conporto EDM proof-ofconcept trial. Study participants were patients attending those clinics; individual patient consent was not obtained. Ethical approval for this secondary data review was obtained from the University of Otago Human Ethics Committee (HD19/061). The project was also reviewed by the Ngāi Tahu research consultation committee.

\section{Derivation of study alerts}

During the proof-of-concept trial, patient clinical notes were retrospectively reviewed to see whether clinicians took action or not after receiving an alert. The review was undertaken initially by a computer programme which scanned the notes and could determine if action was taken depending on the text, e.g. "stop metformin"; further review was undertaken by a GP and a pharmacist if the results from the computer review were ambiguous.

Conporto Health provided information for all alerts recorded in Conporto EDM between 1 January 2018 and 1 July 2019, with patient information retrieved from the general practice records secondary to event data. Figure 1 illustrates the steps for the identification of the study alerts. 2499 event alerts were detected within the study period. We excluded 852 alerts where there was no action data recorded; i.e. the medical records had not been reviewed to determine whether action was taken or not. A further 36 events were excluded which had been coded as "false positive" during the proof-of-concept trial, i.e. after checking the medical records, the initial

Provisional alerts

2499 alerts (2452 patients)

All event alerts detected by Conporto EDM

1 Jan $2018-1$ July 2019

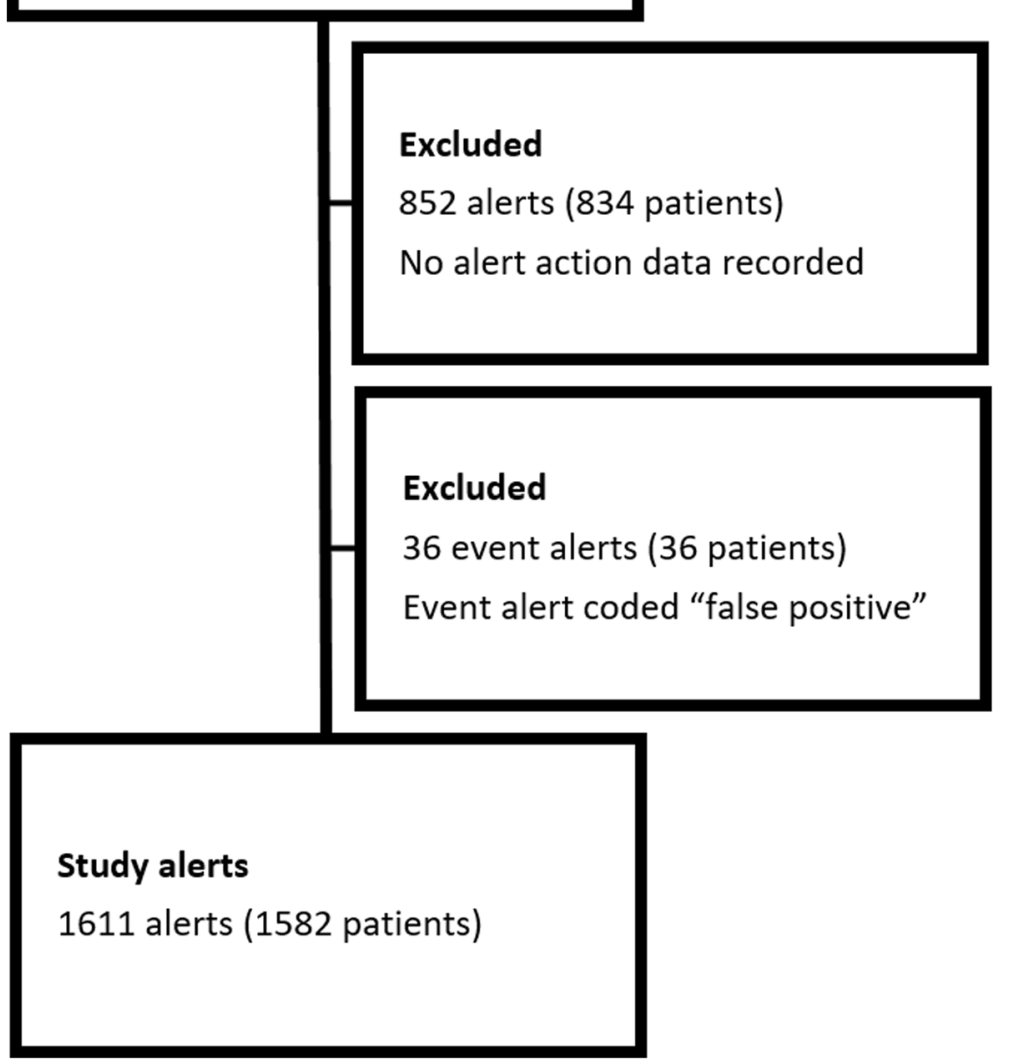

Fig. 1 Derivation of study data 
alert was found to be incorrect. Alert data was linked with patient general practice information held by Conporto, extracted from study general practices using the electronic health record.

\section{Primary outcome}

The primary outcome measure was whether clinicians took action or not after receiving a Conporto EDM alert. All alert types were analysed as one group. Alert consequences were categorised into "action" or "no action taken," as determined by Conporto reviewers during the preliminary analysis period.

\section{Covariates}

Ethnicity is self-identified in New Zealand, and people can identify with more than one ethnic group [24]. Prioritised ethnicity was used in concordance with standard New Zealand health and disability sector use [24]. Patients were categorised to one of the following five categories European, Māori, Pasifika, Asian and Other. "Other" ethnicity in this dataset includes people of Middle Eastern, Latin American and African ethnicities. Deprivation in New Zealand is assessed by geographical meshblock, by combining census data parameters including income, home ownership, and employment (NZDep13) [25]. Patients were assigned to the deprivation groups according to their NZDep13 score, in which deprivation increases by group number. Group 1 (scores 1 and 2) represents the least deprived area; groups 2 (score 3 and 4 ), 3 (5 and 6), and 4 (7 and 8 ) are increasingly deprived, while group 5 (9 and 10) represents the most deprived.

In New Zealand, clinicians highlight long-term diagnoses and long-term medications in their patient's electronic health record in order to provide best practice care and facilitate communication between healthcare providers. Typically, long-term diagnoses refer to conditions that the patient receives active treatment for, and serious historic diagnoses. Long-term medications are those which the patient is prescribed regularly (e.g. every three months).

Demographic data (age at the time of the GP appointment, gender, ethnicity and socioeconomic deprivation) and clinical data (number of long-term diagnoses and number of long-term medications) were extracted from the electronic health records. Age, number of long-term diagnoses and long-term medications were treated as categorical variables. Age was divided into three clinically meaningful groups - those aged 1-49 years, 50-74 years and 75 years and older. Numbers of diagnoses and medications are grouped into three clinically meaningful groups; 1-5 long-term diagnoses or long-term medications, $6-10$, and 11 or more.

\section{Missing data}

Complete data was available for 1235/1611 (76.7\%) events. Information on covariates was missing if it was absent in the general practice records. The covariate with the most missing data was long-term medications (301/1611 events, $18.7 \%)$, followed by socio-economic depreivation $(181 / 1611,11.3 \%)$ and long-term diagnoses $(144 / 1611,8.9 \%)$.

\section{Statistical analyses}

Logistic regression with robust standard error was used to investigate if the actions taken differed across ethnicity groups. Robust standard error allows correlations between the events reported from the same patient. We considered potential confounding by age, gender, socioeconomic deprivation, number of long-term diagnoses, and number of long-term prescriptions. Each covariate was initially fitted separately, then with ethnicity. The final model included all covariates.

Unadjusted and adjusted odd ratios along with $95 \%$ CI were reported for each covariate. Finally, the EDM alerts were analysed by event type. The number and proportion of notified alerts were reported and of those alerted events, those of actioned events were also reported. Complete-case analysis was used for handling missing data and was performed based on 1235 events. All statistical analyses were performed using Stata software version 15.1 [26].

\section{Results}

Table 2 shows events by patient demographic and clinical covariates, by action (whether action was taken or not).

Around half of alerts results in an action (791/1611, $49.1 \%)$. Most alerts occurred in patients aged at least 50 years old $(1313 / 1611,81.5 \%)$ and female (1004/1611, $62.3 \%)$. There was no clear pattern of action taken by age group. Females had proportionally less action taken than males (female action taken 458/1004, 45.6\%; male 333/607, 54.9\%).

NZ European ethnicity constituted $70.6 \%$ of the sample (1137/1611), Māori 241 (15.0\%), Pasifika 82 (5.1\%), Asian 101 (6.3\%) and Other 50 (3.1\%). Patients of Asian ethnicity were proprtionally most likely to have action taken $(59 / 101,58.4 \%)$, and patients of Other ethnicity were least likely to have action taken $(17 / 50,34.0 \%)$. More than $40 \%$ of the sample lived in areas of high deprivation (NZDep13 quintile 4 or $5=692 / 1611$, $43.0 \%)$. There was no clear pattern in the proportion of action taken by deprivation.

The median number of long term diagnoses was 6 (IQR 3-8), and the median number of long-term medication 7 (IQR 4-10). There appeared to be a positive 
Table 2 Table of events by patient demographic and clinical covariates

\begin{tabular}{|c|c|c|c|}
\hline Variable & $\begin{array}{l}\text { No Action } \\
n=820(50.9 \%)^{a}\end{array}$ & $\begin{array}{l}\text { Action } \\
n=791(49.1 \%)^{a}\end{array}$ & $\begin{array}{l}\text { Total } \\
n=1611(100 \%)^{b}\end{array}$ \\
\hline \multicolumn{4}{|l|}{ Age in years } \\
\hline $1-49$ & $166(55.7)$ & $132(44.3)$ & $298(18.5)$ \\
\hline $50-74$ & $351(47.4)$ & $389(52.6)$ & $740(45.9)$ \\
\hline 75 or more & $303(52.9)$ & $270(47.1)$ & $573(35.6)$ \\
\hline Missing & 0 & 0 & 0 \\
\hline \multicolumn{4}{|l|}{ Gender } \\
\hline Male & $274(45.1)$ & $333(54.9)$ & $607(37.7)$ \\
\hline Female & $546(54.4)$ & $458(45.6)$ & $1004(62.3)$ \\
\hline Missing & 0 & 0 & 0 \\
\hline \multicolumn{4}{|c|}{ Prioritised Ethnicity } \\
\hline European & $577(50.8)$ & $560(49.3)$ & $1137(70.6)$ \\
\hline Māori & $128(53.1)$ & $113(46.9)$ & $241(15.0)$ \\
\hline Pasifika & $40(48.8)$ & $42(51.2)$ & $82(5.1)$ \\
\hline Asian & $42(41.6)$ & $59(58.4)$ & $101(6.3)$ \\
\hline Other & $33(66.0)$ & $17(34.0)$ & $50(3.1)$ \\
\hline Missing & 0 & 0 & 0 \\
\hline \multicolumn{4}{|l|}{ Deprivation $^{c}$} \\
\hline 1 & $103(48.6)$ & $109(51.4)$ & $212(13.2)$ \\
\hline 2 & $119(52.2)$ & $109(47.8)$ & $228(14.2)$ \\
\hline 3 & $159(53.4)$ & $139(46.6)$ & $298(18.5)$ \\
\hline 4 & $172(49.7)$ & $174(50.3)$ & $346(21.5)$ \\
\hline 5 & $167(48.3)$ & $179(51.7)$ & $346(21.5)$ \\
\hline Missing & $100(55.3)$ & $81(44.8)$ & $181(11.3)$ \\
\hline \multicolumn{4}{|c|}{ Long-term diagnoses } \\
\hline $1-5$ & $376(52.5)$ & $340(47.5)$ & $716(44.5)$ \\
\hline $6-10$ & $287(49.9)$ & $288(50.1)$ & $575(35.7)$ \\
\hline 11 or more & $75(42.6)$ & $101(57.4)$ & $176(10.9)$ \\
\hline Missing & $82(56.9)$ & $62(43.1)$ & $144(8.9)$ \\
\hline \multicolumn{4}{|c|}{ Long-term medications } \\
\hline $1-5$ & $281(53.3)$ & $246(46.7)$ & $527(32.7)$ \\
\hline $6-10$ & $244(47.0)$ & $275(53.0)$ & $519(32.2)$ \\
\hline 11 or more & $112(42.4)$ & $152(57.6)$ & $264(16.4)$ \\
\hline Missing & $183(60.8)$ & $118(39.2)$ & $301(18.7)$ \\
\hline
\end{tabular}

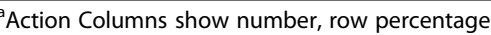

${ }^{\mathrm{b}}$ Total Column shows number, column percentage for each section

'Deprivation: 1 represents the least socioeconomically deprived, 5 the most deprived

trend towards more action taken with increasing number of both long-term diagnoses and long-term medications.

Table 3 shows that the adjusted odds of having action taken for Māori patients was 0.88 (95 \%CI 0.631.22) times that of European patients. Similarly, Pasifika ethnicity was associated with a reduced adjusted odds of receiving actions $(\mathrm{OR}=0.88$, $95 \% \mathrm{CI} 0.52-$
Table 3 The unadjusted and adjusted odds ratios of action for all events taken, by patient characteristics and clinical covariates

\begin{tabular}{|c|c|c|c|c|}
\hline & Unadjusted & & Adjusted & \\
\hline Variable & OR (95 \% Cl) & $p$ value & OR (95 \% Cl) & $p$ value \\
\hline \multicolumn{5}{|l|}{ Age in years } \\
\hline $1-49$ & 1 [Reference] & - & 1 [Reference] & - \\
\hline $50-74$ & $1.39(1.06-1.83)$ & 0.016 & $1.28(0.92-1.79)$ & 0.144 \\
\hline 75 or more & $1.12(0.85-1.48)$ & 0.428 & $1.15(0.80-1.67)$ & 0.446 \\
\hline \multicolumn{5}{|l|}{ Gender } \\
\hline Male & 1 [Reference] & - & 1 [Reference] & - \\
\hline Female & $0.69(0.56-0.85)$ & $<0.001$ & $0.76(0.59-0.96)$ & 0.023 \\
\hline \multicolumn{5}{|l|}{ Ethnicity } \\
\hline European & 1 [Reference] & - & 1 [Reference] & - \\
\hline Māori & $0.91(0.69-1.20)$ & 0.505 & $0.88(0.63-1.22)$ & 0.446 \\
\hline Pasifika & $1.08(0.69-1.69)$ & 0.731 & $0.88(0.52-1.49)$ & 0.646 \\
\hline Asian & $1.45(0.96-2.19)$ & 0.079 & $1.39(0.86-2.23)$ & 0.178 \\
\hline Other & $0.53(0.29-0.96)$ & 0.037 & $1.09(0.43-2.79)$ & 0.851 \\
\hline \multicolumn{5}{|l|}{ Deprivation $^{a}$} \\
\hline 1 & 1 [Reference] & - & 1 [Reference] & - \\
\hline 2 & $0.87(0.60-1.26)$ & 0.450 & $0.82(0.54-1.23)$ & 0.332 \\
\hline 3 & $0.83(0.58-1.18)$ & 0.288 & $0.79(0.54-1.16)$ & 0.231 \\
\hline 4 & $0.96(0.68-1.35)$ & 0.796 & $0.99(0.68-1.45)$ & 0.959 \\
\hline 5 & $1.01(0.72-1.43)$ & 0.942 & $0.98(0.66-1.45)$ & 0.918 \\
\hline
\end{tabular}

Long-term diagnoses

$\begin{array}{lllll}1-5 & 1 \text { [Reference] } & - & 1 \text { [Reference] } & - \\ 6-10 & 1.11(0.89-1.38) & 0.353 & 1.04(0.80-1.35) & 0.792 \\ 11 \text { or more } & 1.49(1.07-2.08) & 0.019 & 1.31(0.87-1.96) & 0.193\end{array}$

Long-term medications

\begin{tabular}{lllll}
$1-5$ & 1 [Reference] & - & 1 [Reference] & - \\
$6-10$ & $1.29(1.01-1.64)$ & 0.042 & $1.16(0.88-1.52)$ & 0.283 \\
11 or more & $1.55(1.15-2.09)$ & 0.004 & $1.25(0.89-1.77)$ & 0.201 \\
\hline
\end{tabular}

aeprivation: 1 represents the least socioeconomically deprived, 5 the most deprived

1.49) compared to Europeans. Although the estimated odds suggest that Māori and Pasifika patients were less likely to be treated, the results are not statistically significant. In addition, patients of Asian ethnicity had increased odds of having action taken (OR 1.39, $95 \%$ CI 0.86-2.23), however the association was not statistically significant.

Women had reduced odds of having action taken compared to men in both the unadjusted and adjusted models. After adjusting for confounding, the odds ratio for women having action taken for an alert was 0.76 (95 \%CI 0.59-0.96). There was no association found between action taken and age, social deprivation, number of long-term diagnoses, or number of long-term medications. 
Table 4 shows that just under half of the events were actioned overall $(791 / 1611,49.1 \%)$. The majority of events were notified $(1358 / 1611,84.3 \%)$. Of those notified, $58.2 \%(791 / 1358)$ were actioned. The most common event detected was co-prescription of a macrolide antibiotic and simvastatin. This accounted for more than one quarter of events (425/ $1611,26.4 \%)$. The least common event was a prescription for buproprion in a patient diagnosed with epilepsy (4/1611, $0.3 \%)$. Excluding buproprion, notification rates ranged from $98.2 \%$ (160/163 females of childbearing age prescribed sodium valporate for epilepsy) to $55.8 \%$ (24/43 patients with low renal function who were prescribed a high dose of allopurinol). Clinicians proportionally took the most action for patients who were taking methotrexate but not folic acid $(98 / 155,63.2 \%)$, and (excluding buproprion) the least action for females of childbearing age taking sodium valproate for epilepsy (48/163, $29.5 \%)$. Individual event action rates (excluding buproprion) following notification ranged from $30.0-87.5 \%$.

\section{Discussion}

\section{Summary of findings}

We found no evidence supporting the assertion that Māori or Pasifika ethnicity groups are associated with lower odds of clinicians taking action after an alert based on the reported confidence intervals. However, the estimated odds ratios do suggest that Māori or Pasifika ethnicity is associated with lower odds of clinicians taking action after an alert. Women had nearly double the number of alerts compared to men, which is consistent with the fact women see their GPs more frequently than men, even after excluding consultations relating to gynaecological and obstetric conditions [27]. Our study suggests that females were less likely to have action taken compared to males following an alert. Women have a long history of experiencing inequitable health care compared to men, such as receiving less pain relief for similar levels of acute and chronic pain $[28,29]$. This may be attributable to the status of women in society; addressing gender equality is considered an important factor in improving women's health [30].

\section{Strengths and limitations}

This paper provides a snapshot of high-needs general practice patients in New Zealand, as well as some of the risks they are exposed to while receiving routine healthcare. This study had a wide geographical spread of patients, and an ethnic distribution profile similar to the New Zealand population, although the study had a lower proportion of Asian patients and a higher proportion of Other ethnicities [31]. A weakness of this study is that it could be underpowered to detect differences by ethnicity. Also, one quarter of participants had at least one missing covariate, and thus were not included in the analysis.

\section{Comparison with existing literature}

The underlying premise of this work was a rich literature demonstrating increased risk of harm and unfair treatment of people based on ethnicity. This is well documented for Māori and Pasifika patients [8, 10]. Migrants and people who don't speak English face additional challenges in a healthcare setting due to cultural and language barriers [32, 33]. In addition, preliminary review of these data led us to anticipate differences in clinician action based on ethnicity.

Our findings suggest patient gender is associated with whether general practice clinicians take action after receiving an alert. It is possible that patient ethnicity also

Table 4 All Conporto EDM Alerts

\begin{tabular}{llll}
\hline Alert & $\begin{array}{l}\text { N } \\
\text { (\% of all events) }\end{array}$ & $\begin{array}{l}\text { Notified } \\
\text { (\% of event) }\end{array}$ & $\begin{array}{l}\text { Actioned } \\
\text { (\% of notified) }\end{array}$ \\
\hline Macrolide \& Simvastatin & $425(26.4)$ & $363(85.4)$ & $239(65.8)$ \\
NSAID eGFR $<45$ & $372(23.1)$ & $302(81.2)$ & $165(54.6)$ \\
Meformin eGFR $<30$ & $187(11.6)$ & $161(86.1)$ & $113(70.2)$ \\
Valproate F & $178(11.1)$ & $157(88.2)$ & $63(40.1)$ \\
Valproate F epilepsy & $163(10.1)$ & $160(98.2)$ & $48(30.0)$ \\
MTX no folic acid & $155(9.6)$ & $118(76.1)$ & $98(83.1)$ \\
PDEi \& Nitrite & $51(3.2)$ & $44(86.3)$ & $29(65.9)$ \\
Allopurinol > 200 mg eGFR $<30$ & $43(2.7)$ & $24(55.8)$ & $21(87.5)$ \\
NSAID, ulcer, no PPI & $33(2.1)$ & $25(75.8)$ & $15(60.0)$ \\
Buproprion epilepsy & $4(0.3)$ & $4(100)$ & $\mathbf{1 3 5 8 ( 8 4 . 3 )}$ \\
Total & $\mathbf{1 6 1 1 ( 1 0 0 )}$ & $\mathbf{7 9 1 ( 5 8 . 2 )}$ \\
\hline
\end{tabular}


has some effect, although our results are not statistically significant. While other factors may be at play, implicit associations of gender and ethnicity can play a role in medical judgement and result in biased provision of care [34-37].

\section{Implications for health policy}

As the proportion of older patients increases in New Zealand general practice, so too do their numbers of long-term conditions and long-term medications $[18,38]$. The burden of multimorbidity is known to be particularly high for Māori and Pasifika patients [39]. These factors add to the complexity of general practice consultations [40]. Targeted alert systems can help busy general practitioners identify patients at greatest risk of experiencing medication-related harm, and take actions to mitigate those risks $[19,41]$. Clinicians in this study took action following receipt of targeted event alerts more often than not. Promoting use of such a system has the potential to reduce medication-related harm in general practice.

Inequitable care is evident throughout the New Zealand health system $[4,10]$. The causes for this are multifactorial; no doubt racism and sexism contribute to health inequities, adverse patient experiences and negative health outcomes [42, 43]. While addressing these issues at a system level is important [10], this paper focussed on the action of individual clinicians. Training clinicians to speak up against racism and sexism, as well as recognise their own implicit biases, may help reduce inequities based on those characteristics [34, 44-46].

\section{Conclusions}

This analysis of data arising from a general practice electronic alert system in New Zealand assessed whether clinicians took action on those alerts. Clinicians typically did take action. Our study has found no evidence to support the assertion that Māori and Pasifika ethnicity are associated with lower odds of having action taken on an alert, although the adjusted odds ratios suggest these ethnicity groups are associated with a lower odds, and therefore future studies would benefit from larger samples to investigate this research question further. Female sex is also associated with lower odds of having action taken. Recognising clinician biases may improve the equitability of health care provision.

\footnotetext{
Abbreviations

Conporto EDM: Conporto Health Event Detection \& Mitigation system; GP: General practitioner; NZ: New Zealand; EHR: Electronic Health Record
}

\section{Supplementary Information}

The online version contains supplementary material available at https://doi. org/10.1186/s12939-021-01461-y.

Additional file 1.

\section{Acknowledgements}

This project would not have been possible without the support of Conporto Health Ltd who engaged in discussions around patient safety stimulating this research, and provided their data for analysis.

\section{Authors' contributions}

SL designed the study, analysed the data and wrote the manuscript. JZ provided guidance regarding the statistical analyses and critically reviewed the manuscript. AS and TS critically reviewed the study design and manuscript. The author(s) read and approved the final manuscript.

\section{Authors' information}

$\mathrm{SL}$ is a PhD Candidate; this work has beenundertaken as part of her PhD thesis. TS, AS and JZ are her PhD Supervisors.

\section{Funding}

This work was completed as part of SL's Clinical Research Training Fellowship funded by the Health Research Council of New Zealand (HRC 18-031). The Health Research Council had no input in the design of the study and collection, analysis, and interpretation of data, nor in writing the manuscript.

\section{Availability of data and materials}

The anonymised datasets analysed during the current study are attached as a supplementary file.

\section{Declarations}

Ethics approval and consent to participate

Consent and data access were granted by Conporto Health, which has an existing research agreement with a network of New Zealand general practices. This research was approved by the University of Otago ethics committee (HD19/061), and reviewed by the Ngāi Tahu Research Consultation Committee.

\section{Consent for publication}

Not applicable.

\section{Competing interests}

The authors declare that they have no competing interests.

\section{Author details}

'Department of General Practice and Rural Health, Otago Medical School Dunedin Campus, University of Otago, Dunedin, New Zealand. ${ }^{2}$ Department of Preventive and Social Medicine, Otago Medical School - Dunedin Campus, University of Otago, Dunedin, New Zealand. 'S School of Pharmacy, University of Otago, Dunedin, New Zealand.

Received: 17 December 2020 Accepted: 29 April 2021

Published online: 11 May 2021

\section{References}

1. Braveman P. Health Disparities and Health Equity: Concepts and Measurement. Annu Rev Public Health. 2006;27(1):167-94.

2. Medical Council New Zealand. He Ara Hauora Māori: A Pathway to Māori Health Equity. Medical Council of New Zealand. https://www.mcnz.org.nz/a ssets/standards/6c2ece58e8/He-Ara-Hauora-Maori-A-Pathway-to-Maori-Hea Ith-Equity.pdf. Published 2019. Accessed Nov 2019.

3. Reid P, Paine S-J, Curtis E, et al. Achieving health equity in Aotearoa: strengthening responsiveness to Māori in health research. NZ Med J. 2017; 130(1465):96-103.

4. Goodyear-Smith F, Ashton T. New Zealand health system: universalism struggles with persisting inequities. Lancet. 2019;394(10196):432-42.

5. Gauld R. International Health Care System Profiles New Zealand. The Commonwealth Fund. https://www.commonwealthfund.org/internationalhealth-policy-center/countries/new-zealand\#reducing-disparities. Published 2020. Accessed 1 April 2021

6. OECD Data. Health Spending. OECD. https://data.oecd.org/healthres/healthspending.htm. Published 2019. Accessed 1 April 2021.

7. Stats New Zealand. Labour market statistics (income): June 2020 quarter. https://www.stats.govt.nz/information-releases/labour-market-statisticsincome-june-2020-quarter. Published 2020. Accessed 1 April 2021. 
8. Simpson H. Health and Disability System Review. Final Report. Pūrongo Whakamutunga. Wellington: Health and Disability System Review; 2020.

9. Ministry of Health. Statement of Intent 2015 to 2019. Wellington: Ministry of Health; 2015.

10. Chin MH, King PT, Jones RG, et al. Lessons for achieving health equity comparing Aotearoa/New Zealand and the United States. Health Policy. 2018;122(8):837-53.

11. Dawson P, Jaye C, Gauld R, Hay-Smith J. Barriers to equitable maternal health in Aotearoa New Zealand: an integrative review. Int J Equity Health. 2019;18(1):168

12. Ministry of Health. Publicly funded hospital discharges - 1 July 2012 to 30 June 2013. New Zealand Government. http://www.health.govt.nz/publica tion/publicly-funded-hospital-discharges-1-july-2012-30-june-2013. Published 2015. Accessed 15 Jan 2020.

13. Tobias M, Turley M, Liu M. Health loss in New Zealand: A report from the New Zealand burden of diseases, injuries and risk factors study, 2006-2016. Wellington: Ministry of Health; 2013.

14. Derrett S, Wilson S, Samaranayaka A, et al. Prevalence and predictors of disability 24-months after injury for hospitalised and non-hospitalised participants: results from a longitudinal cohort study in New Zealand. PloS One. 2013;8(11):e80194

15. Davis P, Lay-Yee R, Dyall L, et al. Quality of hospital care for Māori patients in New Zealand: retrospective cross-sectional assessment. Lancet. 2006; 367(9526):1920-5

16. Health Quality \& Safety Commission New Zealand. Gout. Health Quality \& Safety Commission New Zealand. Atlas of Healthcare Variation Web site. https://www.hqsc.govt.nz/our-programmes/health-quality-evaluation/ projects/atlas-of-healthcare-variation/gout/. Published 2018. Accessed 7 Jan 2020.

17. Metcalfe S, Beyene $\mathrm{K}$, Urlich J, et al. Te Wero tonu-the challenge continues: Maori access to medicines 2006/07-2012/13 update. N Z Med J. 2018; 131(1485):27-47.

18. Nishtala PS, Salahudeen MS. Temporal Trends in Polypharmacy and Hyperpolypharmacy in Older New Zealanders over a 9-Year Period: 20052013. Gerontology. 2015;61(3):195-202.

19. Cresswell K, Majeed A, Bates DW, Sheikh A. Computerised decision support systems for healthcare professionals: an interpretative review. J Innov Health Inform. 2013;20(2):115-28.

20. Reis WC, Bonetti AF, Bottacin WE, et al. Impact on process results of clinical decision support systems (CDSSs) applied to medication use: overview of systematic reviews. Inf Technol. 2017;15(4):11.

21. Schedlbauer A, Prasad V, Mulvaney C, et al. What Evidence Supports the Use of Computerized Alerts and Prompts to Improve Clinicians' Prescribing Behavior? J Am Med Inform Assoc. 2009;16(4):531-8.

22. Kwan JL, Lo L, Ferguson J, et al. Computerised clinical decision support systems and absolute improvements in care: meta-analysis of controlled clinical trials. BMJ. 2020;370:m3216.

23. Conporto Health. Conporto EDM (Event Detection \& Mitigation) Proof of Concept: Final Report. Patients First;2018.

24. Health Information Standards Authority. HISO 10001:2017 Ethnicity Data Protocols. 2 ed. Wellington: Ministry of Health; 2017.

25. Atkinson J, Salmond C, Crampton P. NZDep2013 Index of Deprivation Dunedin: University of Otago; 2014

26. Stata Statistical Software: Release 15 [computer program]. College Station: StataCorp LLC; 2017.

27. Jatrana $\mathrm{S}$, Crampton $\mathrm{P}$. Gender differences in general practice utilisation in New Zealand. J Prim Health Care. 2009;1(4):261-9.

28. Chen EH, Shofer FS, Dean AJ, et al. Gender disparity in analgesic treatment of emergency department patients with acute abdominal pain. Acad Emerg Med. 2008;15(5):414-8

29. Samulowitz A, Gremyr I, Eriksson E, Hensing G. "Brave men" and "emotional women": A theory-guided literature review on gender bias in health care and gendered norms towards patients with chronic pain. Pain Res Manag. 2018;6358624:1-14. https://doi.org/10.1155/2018/6358624

30. King TL, Kavanagh A, Scovelle AJ, Milner A. Associations between gender equality and health: a systematic review. Health Promot Int. 2020;35(1):27-41.

31. Stats New Zealand. 2013 Census QuickStats about culture and identity http://archive.stats.govt.nz/Census/2013-census/profile-and-summaryreports/ethnic-profiles.aspx. Published 2014. Accessed Feb 42020.
32. Suphanchaimat R, Kantamaturapoj K, Putthasri W, Prakongsai P. Challenges in the provision of healthcare services for migrants: a systematic review through providers' lens. BMC Health Serv Res. 2015;15(1):390.

33. Garrett PW, Dickson HG, Young L, Whelan AK. "The Happy Migrant Effect": perceptions of negative experiences of healthcare by patients with little or no English: a qualitative study across seven language groups. Qual Saf Health Care. 2008;17(2):101-3.

34. FitzGerald C, Hurst S. Implicit bias in healthcare professionals: a systematic review. BMC Med Ethics. 2017;18(1):19.

35. Hall WJ, Chapman MV, Lee KM, et al. Implicit racial/ethnic bias among health care professionals and its influence on health care outcomes: a systematic review. Am J Public Health. 2015;105(12):e60-76.

36. Sen G, Östlin P. Gender inequity in health: why it exists and how we can change it. Global Public Health. 2008;3(sup1):1-12.

37. Travis CB, Howerton DM, Szymanski DM. Risk, Uncertainty, and Gender Stereotypes in Healthcare Decisions. Women Ther. 2012;35(3-4):207-20.

38. Tomlin AM, Woods DJ, Reid JJ, Tilyard MW. Trends in prescription medicine use by older people in New Zealand 2010-2015: a national populationbased study. N Z Med J. 2020;133(1513):61-6.

39. Stokes T, Azam M, Noble FD. Multimorbidity in Māori and Pacific patients: cross-sectional study in a Dunedin general practice. J Prim Health Care. 2018;10(1):39-43.

40. Stokes T, Tumilty E, Doolan-Noble F, Gauld R. Multimorbidity, clinical decision making and health care delivery in New Zealand Primary care: a qualitative study. BMC Fam Pract. 2017;18(1):51.

41. Van de Velde S, Heselmans A, Delvaux N, et al. A systematic review of trials evaluating success factors of interventions with computerised clinical decision support. Impl Sci. 2018;13(1):114

42. Cormack D, Stanley J, Harris R. Multiple forms of discrimination and relationships with health and wellbeing: findings from national crosssectional surveys in Aotearoa/New Zealand. Int J Equity Health. 2018; 17(1):26.

43. Yeung $\mathrm{P}$, Breheny $\mathrm{M}$. Using the capability approach to understand the determinants of subjective well-being among community-dwelling older people in New Zealand. Age Ageing. 2016:45(2):292-8.

44. Watt $K$, Abbott $P$, Reath J. Developing cultural competence in general practitioners: an integrative review of the literature. BMC Fam Pract. 2016; 17(1):158.

45. White AA, Logghe HJ, Goodenough DA, et al. Self-awareness and cultural identity as an effort to reduce bias in medicine. J Racial Ethn Health Disparities. 2018;5(1):34-49.

46. Simmonds S, Carter M, Preval N, Wilson R. Baseline Data Capture: Cultural Safety, Partnership and Health Equity Initiatives Medical Council of New Zealand; 2020.

\section{Publisher's Note}

Springer Nature remains neutral with regard to jurisdictional claims in published maps and institutional affiliations.
Ready to submit your research? Choose BMC and benefit from:

- fast, convenient online submission

- thorough peer review by experienced researchers in your field

- rapid publication on acceptance

- support for research data, including large and complex data types

- gold Open Access which fosters wider collaboration and increased citations

- maximum visibility for your research: over $100 \mathrm{M}$ website views per year

At $\mathrm{BMC}$, research is always in progress.

Learn more biomedcentral.com/submission 